\title{
Epidemiological analysis of 9,596 patients with acute lung injury at Chinese Military Hospitals
}

\author{
DAIJUN ZHOU, JUN QIU, YI LIANG, WEI DAI, DANFENG YUAN and JIHONG ZHOU

\begin{abstract}
State Key Laboratory of Trauma, Burns and Combined Injury, Department 4, Institute of Surgery Research, Daping Hospital, Third Military Medical University, Chongqing 400042, P.R. China
\end{abstract}

Received April 27, 2015; Accepted June 20, 2016

DOI: $10.3892 /$ etm.2017.4068

\begin{abstract}
Acute lung injury (ALI) is a common and severe disease that has been associated with significant morbidity and mortality. Understanding the epidemiology of ALI is vital for its prevention and treatment. The present study aimed to analyze the epidemiology of ALI by collecting data from patients that were submitted between 2000 and 2008 into the 'No. 1 Military Medical Project' information system. A total of 9,596 ALI patients were analyzed retrospectively, including 7,284 males $(75.91 \%)$ and 2,312 females $(24.09 \%)$. The median age of the patients was 44 years (interquartile range, 31-63 years), and there was a significant difference between the median ages of male and female patients $(\mathrm{P}<0.01)$. The number of patients with ALI admitted to the hospitals showed an increasing trend over time. However, there was no significant difference in the annual gender distribution $(\mathrm{P}>0.05)$. In addition, ALI was more prevalent in May, July, August, October, November and December, as compared with the other months. ALI occurred at any age, although 40-years-old was the peak age. There was a significant difference in the age group distributions of male and female ALI patients $(\mathrm{P}<0.01)$. Among the predisposing conditions, pulmonary contusion represented the highest proportion (45.71\%), followed by pneumonia or respiratory tract infection $(23.68 \%)$ and pulmonary malignant tumor (6.30\%). Of the $581(6.05 \%)$ mortalities, pneumonia was the most common cause $(37.87 \%)$, followed by malignancies $(16.87 \%)$ and pulmonary embolism (11.02\%). However, the highest mortality rate was associated with cardiopulmonary resuscitation $(48.28 \%)$. In conclusion, the results of the present study suggested that ALI should be increasingly monitored in the future, and predisposing conditions should be regarded as
\end{abstract}

Correspondence to: Professor Jihong Zhou, State Key Laboratory of Trauma, Burns and Combined Injury, Department 4, Institute of Surgery Research, Daping Hospital, Third Military Medical University, 30 Gaotanyan Street, Chongqing 400042, P.R. China E-mail:wbrst@tom.com

Key words: acute lung injury, epidemiology, mortality, fatality, predisposing conditions, China one of the most important features determining the management of ALI.

\section{Introduction}

Acute lung injury (ALI), which is a common and severe syndrome that has been associated with various types of lung diseases, is characterized by a low lung compliance, widespread capillary leakage, a low blood oxygen level (hypoxemia), the development of non-cardiogenic pulmonary edema, progressive respiratory failure and a requirement for mechanical ventilation $(1,2)$. In various studies, the mortality rate of ALI has been reported to be considerably high, at $\sim 40 \%$ (3-6).

The etiology and incidence of ALI have not yet been well characterized (7). Previous studies have demonstrated that ALI is caused by local or systemic inflammation triggered by any event, such as local or systemic inflammation, for example malignancies $(8,9)$. Furthermore, the incidence of ALI was reported to be $1.5-100$ cases per 100,000 people per year $(4,8,9)$. In order to improve the outcome of ALI, a good understanding of its underlying epidemiology is required. At present, there are no comprehensive data available regarding its epidemiology in China.

In line with the requirements of all level military hospitals, the Information Center of the Medical Department under the Ministry of General Logistics of the Chinese People's Liberation Army (PLA) has designed and developed a standardized comprehensive hospital information system, named the 'No. 1 Military Medical Project'. This information system comprises three main functional modules that cover the major management functions of a hospital and key clinical procedures, including management of the patient information, medical economic issues and medical materials. Since their launch in September 1995, the general hospitals of the Chinese PLA, including 200 military hospitals and $>100$ civil hospitals, have applied the 'No. 1 Military Medical Project' information system. The included hospitals regularly submit information from this system to the Information Center of the Medical Department, Ministry of General Logistics of the PLA. In the present study, this system provided comprehensive information for ALI patients at all the included hospitals, such that an analysis of the epidemiology of ALI could be implemented. 
Table I. Distribution of gender by age and time.

\begin{tabular}{|c|c|c|c|c|c|}
\hline Parameter & Male, n (\%) & Female, n (\%) & $\chi^{2}$ test & P-value & c-value \\
\hline Year & & & 7.066 & 0.529 & 0.027 \\
\hline 2000 & $120(1.65)$ & $33(1.43)$ & & & \\
\hline 2001 & $442(6.07)$ & $141(6.10)$ & & & \\
\hline 2002 & $573(7.87)$ & $167(7.22)$ & & & \\
\hline 2003 & $671(9.21)$ & $209(9.04)$ & & & \\
\hline 2004 & 757 (10.39) & $215(9.30)$ & & & \\
\hline 2005 & $831(11.41)$ & $266(11.51)$ & & & \\
\hline 2006 & $1,059(14.54)$ & 328 (14.19) & & & \\
\hline 2007 & 1,301 (17.86) & $422(18.25)$ & & & \\
\hline 2008 & $1,530(21.00)$ & $531(22.97)$ & & & \\
\hline Month & & & 23.630 & 0.014 & 0.050 \\
\hline January & $501(6.88)$ & $195(8.43)$ & & & \\
\hline February & $434(5.96)$ & $174(7.53)$ & & & \\
\hline March & $548(7.52)$ & $152(6.57)$ & & & \\
\hline April & $612(8.40)$ & $186(8.04)$ & & & \\
\hline May & $670(9.20)$ & $193(8.35)$ & & & \\
\hline June & $575(7.89)$ & $185(8.00)$ & & & \\
\hline July & $653(8.96)$ & $231(9.99)$ & & & \\
\hline August & $668(9.17)$ & $212(9.17)$ & & & \\
\hline September & $614(8.43)$ & $185(8.00)$ & & & \\
\hline October & $658(9.03)$ & $200(8.65)$ & & & \\
\hline November & $682(9.36)$ & $182(7.87)$ & & & \\
\hline December & $669(9.18)$ & $217(9.39)$ & & & \\
\hline Age group (years) & & & 596.574 & 0.242 & $<0.001$ \\
\hline$<10$ & $417(5.72)$ & $233(10.08)$ & & & \\
\hline $10-19$ & $503(6.91)$ & $81(3.50)$ & & & \\
\hline $20-29$ & $1,004(13.78)$ & $156(6.75)$ & & & \\
\hline $30-39$ & $1,478(20.29)$ & 249 (10.77) & & & \\
\hline $40-49$ & $1,322(18.15)$ & $294(12.72)$ & & & \\
\hline $50-59$ & 968 (13.29) & $303(13.11)$ & & & \\
\hline $60-69$ & $581(7.98)$ & 292 (12.63) & & & \\
\hline $70-79$ & $649(8.91)$ & 402 (17.39) & & & \\
\hline 80-101 & $362(4.97)$ & $302(13.06)$ & & & \\
\hline Total & $7,284(75.91)$ & $2,312(24.09)$ & & & \\
\hline
\end{tabular}

The aim of the present study was to establish the frequency, etiologies and mortality rates of patients with ALI admitted to the Chinese Military Hospitals between January 2000 and December 2008. The results of the present study may provide guidance for the development of prevention and therapeutic strategies for ALI.

\section{Materials and methods}

Data collection. Data used in the present study were directly derived from the 'No. 1 Military Medical Project' information system and corresponded to between January 2000 and December 2008. A retrospective analysis of all ALI inpatients at 10 Chinese Military Hospitals was conducted. Hospital admission ALI data were extracted, and inpatients and outpatients not diagnosed with ALI as the primary disease were excluded from the present study. Data regarding gender, age, time distribution, predisposing conditions and outcome were reviewed. The present study was approved by the Institutional Review Board of Daping Hospital (Third Military Medical University, Chongqing, China), and patient records/information were anonymized and de-identified prior to analysis.

Statistical analysis. All analyses were performed using SPSS version 17.0 software (SPSS Inc., Chicago, IL, USA). Categorical variables were analyzed using $\chi^{2}$ tests. The $\chi^{2}$ value may have been overrepresented due to the large sample size, since the value is based on the strength of an association and the size of a sample. In order to modify the easily achieved statistical 
Table II. Predisposing conditions and clinical risk factors for 9,596 patients, including 581 deceased patients, with acute lung injury.

\begin{tabular}{|c|c|c|c|}
\hline Condition & Patients, n (\%) & Deceased, n (\%) & Mortality rate $(\%)$ \\
\hline Pulmonary encephalopathy & $9(0.09)$ & $1(0.17)$ & 11.11 \\
\hline Pulmonary cyst & $15(0.16)$ & $0(0.00)$ & 0.00 \\
\hline Pulmonary fibrosis & $20(0.21)$ & $4(0.69)$ & 20.00 \\
\hline Shock & $43(0.45)$ & $13(2.24)$ & 30.23 \\
\hline Closed pulmonary baro-trauma & $46(0.48)$ & $3(0.52)$ & 6.52 \\
\hline Cardiopulmonary resuscitation & $58(0.60)$ & $28(4.82)$ & 48.28 \\
\hline Cor pulmonale & $61(0.64)$ & $10(1.72)$ & 16.39 \\
\hline Pneumothorax & $70(0.73)$ & $2(0.34)$ & 2.86 \\
\hline Pulmonary collapse & $101(1.05)$ & $4(0.69)$ & 3.96 \\
\hline Lung foreign body & $131(1.37)$ & $2(0.34)$ & 1.53 \\
\hline Emphysema & $136(1.42)$ & $5(0.86)$ & 3.68 \\
\hline Pulmonary embolism & $140(1.46)$ & $64(11.02)$ & 45.71 \\
\hline Surgery & $179(1.87)$ & $16(2.75)$ & 8.94 \\
\hline Other & $184(1.92)$ & $17(2.93)$ & 9.24 \\
\hline Acute lung edema & $256(2.67)$ & $8(1.38)$ & 3.13 \\
\hline Tuberculosis & $300(3.13)$ & $3(0.52)$ & 1.00 \\
\hline Trauma & $584(6.09)$ & $20(3.44)$ & 3.42 \\
\hline Malignancy & $605(6.30)$ & $98(16.87)$ & 16.20 \\
\hline Pneumonia & $2,272(23.68)$ & $220(37.87)$ & 9.68 \\
\hline Pulmonary contusion & $4,386(45.71)$ & $63(10.84)$ & 1.44 \\
\hline Total & $9,596(100.0)$ & $581(100.0)$ & - \\
\hline
\end{tabular}

value, the contingency coefficient was introduced as a valuable statistic. Quantitative variables with a skewed distribution were presented as the median and interquartile range (IQR). $\mathrm{P}<0.05$ was considered to indicate a statistically significant difference.

\section{Results}

Demographic data. As shown in Table I, a total of 9,596 patients with ALI were admitted to the Chinese Military Hospitals between January 2000 and December 2008. Among the patients, 7,284 (75.91\%) were male and 2,312 (24.09\%) were female (Table I). The median age for all patients was 44 years (IQR, 31-63 years). The median age in males was 42 years (IQR, 30-57 years), while in females it was 55 years (IQR, 36-73 years). A significant difference in median age was detected $(\mathrm{P}<0.001)$.

Time distribution. The number of patients with ALI admitted to the Chinese Military Hospitals exhibited an increasing trend over time, as shown in Fig. 1. There was no significant difference in the gender distribution of ALI incidence among the years of admission $(\mathrm{P}=0.529, c=0.027$; Table I). Conversely, there was a significant difference in the gender distribution among the months of admission $(\mathrm{P}=0.014, c=$ 0.050; Table I). As shown in Fig. 2, the incidence of ALI was more prevalent in May, July, August, October, November and December, as compared with the other months of the year (Fig. 2).
Table III. Outcomes of 9,596 patients with acute lung injury.

\begin{tabular}{lc}
\hline Outcome & Patients, $\mathrm{n}(\%)$ \\
\hline Recovered & $5,446(56.75)$ \\
Improved & $3,108(32.39)$ \\
Invalid & $114(1.19)$ \\
Untreated & $139(1.45)$ \\
Mortality & $581(6.05)$ \\
Other & $208(2.17)$ \\
\hline
\end{tabular}

Age distribution. The age distribution of the total ALI admissions between 2000 and 2008 is shown in Fig. 3. Patients admitted to the Chinese Military Hospitals with ALI were aged between 1 and 101 years. The peak proportion was observed at $\sim 40$ years of age.

Predisposing conditions and risk factors for ALI development. Among the 9,596 hospital admission cases with available details on predisposing conditions or risk factors, the majority of cases presented pulmonary contusion $(45.71 \%)$, followed by pneumonia or respiratory tract infections $(23.68 \%)$ and pulmonary malignant tumors $(6.30 \%)$, as shown in Table II.

Outcome and mortality. Among the 9,596 patients admitted to the Chinese Military Hospitals between 2000 and 2008, $5,446(56.75 \%)$ were reported as fully recovered, $3,108(32.39 \%)$ 


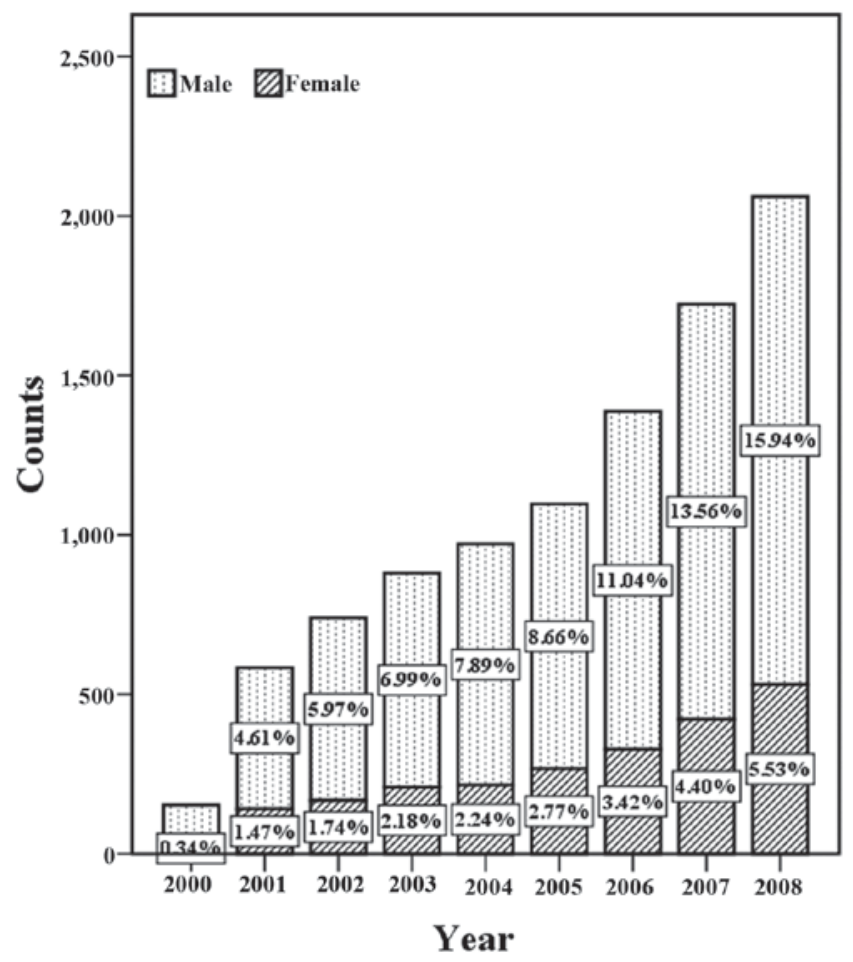

Figure 1. Annual admission of patients with acute lung injury at Chinese Military Hospitals.

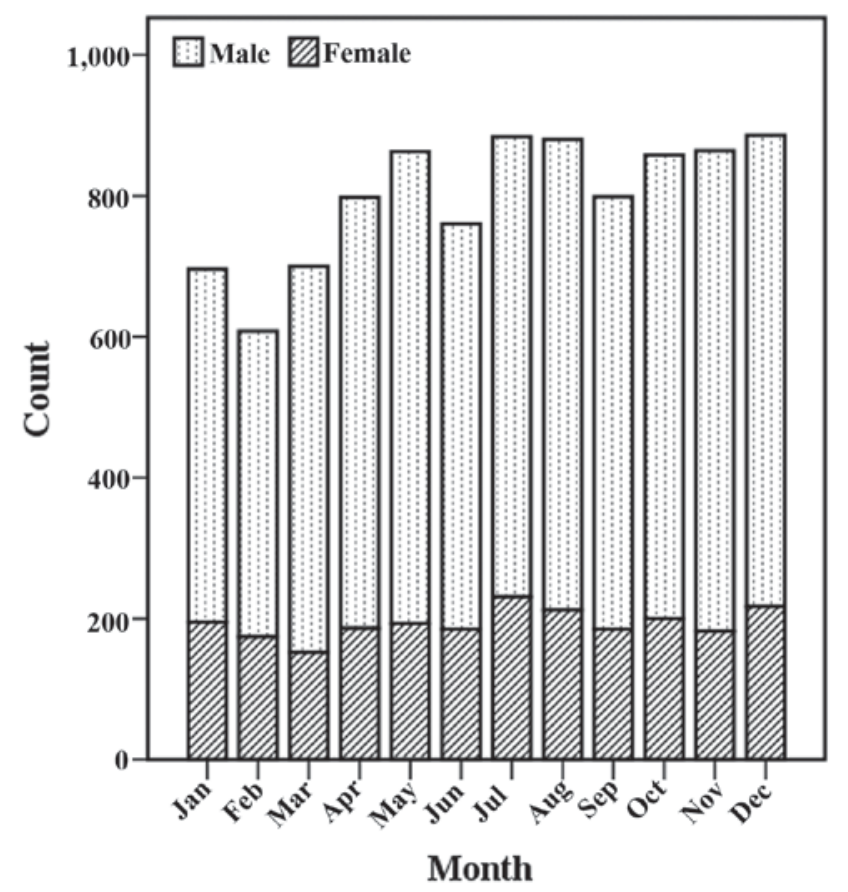

Figure 2. Total monthly admissions of patients with acute lung injury between January 2000 and December 2008.

were reported as improved, $114(1.19 \%)$ were deemed invalid, $139(1.45 \%)$ were untreated and $581(6.05 \%)$ were reported as mortalities (Table III).

In the 581 mortality cases, pneumonia constituted the most common cause $(37.87 \%)$, followed by malignancies $(16.87 \%)$ and pulmonary embolism (11.02\%), as shown in Fig. 4. In addition, Table II shows the proportions of deceased patients

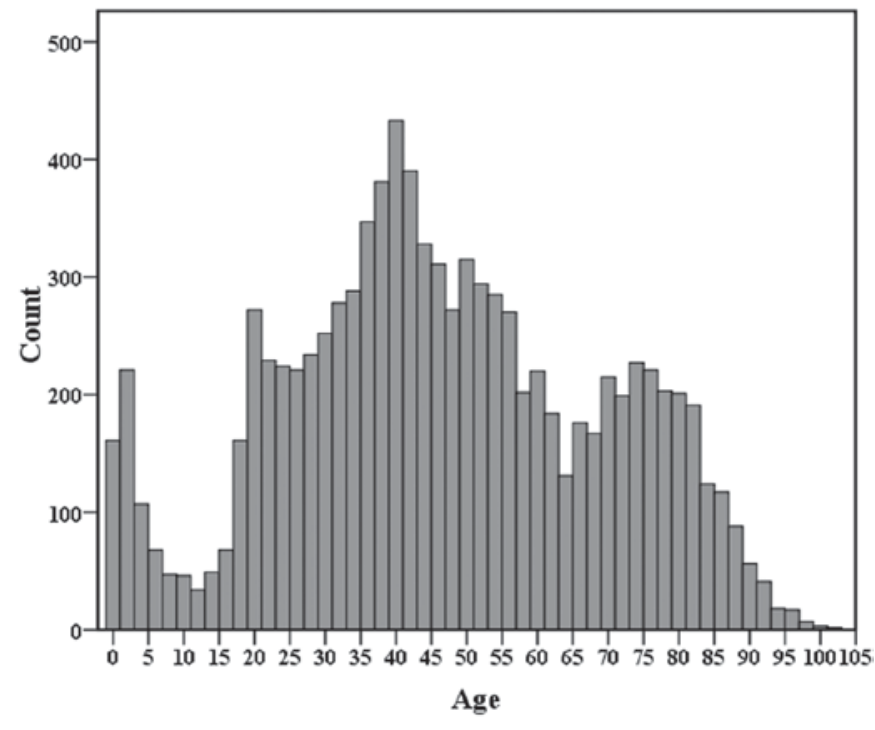

Figure 3. Age distribution of 9,596 patients admitted to Chinese Military Hospitals with acute lung injury between 2000 and 2008.
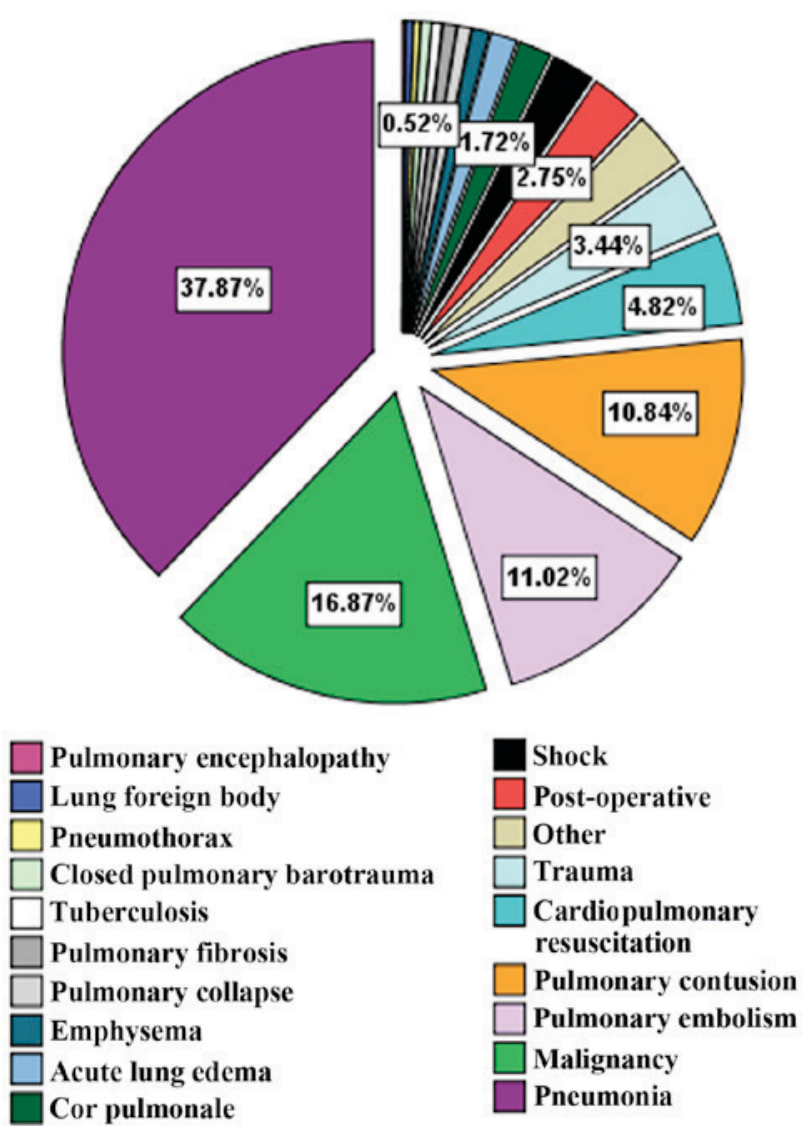

Figure 4. Predisposing conditions and clinical risk factors of deceased patients with acute lung injury.

with particular predisposing conditions or clinical risk factors, and their associated mortality rates.

\section{Discussion}

Accurate epidemiological data are essential to provide pilot data and to assess the feasibility of performing clinical 
trials (10). The results of the present study may provide important information for clinicians and health regulators worldwide regarding the prevention and treatment of ALI.

The incidence of ALI is a key point in epidemiology and is important for its diagnosis and management (7). However, due to the unclear population size, the present study was unable to calculate the incidence of ALI.

ALI is a common disease among critically ill patients, in whom it has a marked effect on morbidity and mortality. Several issues concerning the epidemiology of ALI require improvement, such as patient characteristics, presentation and mortality. The present study aimed to investigate the epidemiology of ALI in 9,596 patients admitted to Chinese Military Hospitals between 2000 and 2008. Notably, the incidence of ALI was found to be higher in males, as compared with females. We speculated that gender-based differences existed at clinical presentation prior to ALI. Furthermore, the median age of male patients was 44 years, whereas the median age of female patients was 55 years. ALI occurred among all ages, although the peak incidence was at $\sim 40$ years.

The current study demonstrated that ALI-associated admissions to the Chinese Military Hospitals showed an increasing trend between 2000 and 2008. The underlying reason for this was unclear, although it may suggest that ALI should be increasingly monitored in the future. In addition, ALI admissions were more prevalent in May, July, August, October, November and December, as compared with the other months, which may be due to the predisposing conditions of ALI. Further studies are required to analyze these predisposing conditions of ALI.

Various risk factors associated with ALI, such as severe pulmonary dysfunction, neoadjuvant chemotherapy, and chronic alcohol consumption, have been reported in previous studies (11-17). The present study analyzed the predisposing conditions of 9,596 patients with ALI, including pulmonary encephalopathy, pulmonary cyst, shock, cardiopulmonary resuscitation, pneumonia and trauma. It was demonstrated that pulmonary contusion was the most common predisposing condition for ALI, followed by pneumonia or respiratory tract infections, and then pulmonary malignant tumors. These results suggested that the incidence of ALI may vary greatly depending on the predisposing condition. Although the association of predisposing conditions with the severity of ALI remains debated, the existence of a predisposing condition was regarded as one of the most important features based on incidence.

The present study demonstrated that the crude mortality rate of all hospitalized patients with ALI was $6.05 \%$. The morbidity and mortality rates of ALI have previously been associated with its predisposing conditions (15). Furthermore, a previous study reported that the mortality rate of ALI is evidently high (6). In the present study, cardiopulmonary resuscitation was associated with the highest mortality rate (48.28\%) among all the predisposing conditions and clinical risk factors. Although the highest proportion of mortalities for that period were attributed to pneumonia, the mortality rate for patients with pneumonia and ALI was only 9.68\%. These results suggested that the mortality rate of ALI is predominantly associated with the underlying disease, including the degree of organ dysfunction and the severity. However, treatment of ALI should focus on efficiently dealing with the predisposing conditions.

In conclusion, the findings of the present study demonstrated an increased trend in ALI admission with a majority of middle-aged patients. The majority of ALI cases presented with pulmonary contusion. The average mortality rate for ALI was $6.05 \%$ and the major causes of death were pneumonia followed by malignancies. The results of the present study provided novel information regarding the epidemiology of ALI, and offer potential insight into future areas for improving the clinical care and investigation of ALI.

\section{Acknowledgements}

The authors of the present study would like to thank the patients who participated in the study, and the laboratory technicians for their valuable efforts.

\section{References}

1. ARDS Definition Task Force, Ranieri VM, Rubenfeld GD, Thompson BT, Ferguson ND, Caldwell E, Fan E, Camporota L and Slutsky AS: Acute respiratory distress syndrome: The Berlin Definition. JAMA 307: 2526-2533, 2012.

2. Bernard GR, Artigas A, Brigham KL, Carlet J, Falke K, Hudson L, Lamy M, Legall JR, Morris A and Spragg R: The American-European consensus conference on ARDS. Definitions, mechanisms, relevant outcomes, and clinical trial coordination. Am J Respir Crit Care Med 149: 818-824, 1994.

3. Vasilyev S, Schaap RN and Mortensen JD: Hospital survival rates of patients with acute respiratory failure in modern respiratory intensive care units. An international, multicenter, prospective survey. Chest 107: 1083-1088, 1995.

4. Lewandowski K, Metz J, Deutschmann C, Preiss H, Kuhlen R, Artigas A and Falke KJ: Incidence, severity and mortality of acute respiratory failure in Berlin, Germany. Am J Respir Crit Care Med 151: 1121-1125, 1995.

5. Phua J, Badia JR, Adhikari NK, Friedrich JO, Fowler RA, Singh JM, Scales DC, Stather DR, Li A, Jones A, et al: Has mortality from acute respiratory distress syndrome decreased over time?: A systematic review. Am J Respir Crit Care Med 179: 220-227, 2009.

6. Luhr OR, Antonsen K, Karlsson M, Aardal S, Thorsteinsson A Frostell CG and Bonde J: Incidence and mortality after acute respiratory failure and acute respiratory distress syndrome in Sweden, Denmark and Iceland. The ARF Study Group. Am J Respir Crit Care Med 159: 1849-1861, 1999.

7. Frutos-Vivar F, Nin N and Esteban A: Epidemiology of acute lung injury and acute respiratory distress syndrome. Curr Opin Crit Care 10: 1-6, 2004.

8. Webster NR, Cohen AT and Nunn JF: Adult respiratory distress syndrome-how many cases in the UK? Anaesthesia 43: 923-926, 1988.

9. Fowler AA, Hamman RF, Good JT, Benson KN, Baird M, Eberle DJ, Petty TL and Hyers TM: Adult respiratory distress syndrome: Risk with common predispositions. Ann Intern Med 98: 593-597, 1983.

10. Irish Critical Care Trials Group: Acute lung injury and the acute respiratory distress syndrome in Ireland: A prospective audit of epidemiology and management. Crit Care 12: R30, 2008.

11. Roupie E, Lepage E, Wysocki M, Fagon JY, Chastre J, Dreyfuss D, Mentec H, Carlet J, Brun-Buisson C, Lemaire F and Brochard L: Prevalence, etiologies and outcome of the acute respiratory distress syndrome among hypoxemic ventilated patients. SRLF collaborative group on mechanical ventilation. Société de Réanimation de Langue Française. Intensive Care Med 25: 920-929, 1999.

12. Suchyta MR, Clemmer TP, Elliott CG, Orme JF Jr and Weaver LK: The adult respiratory distress syndrome. A report of survival and modifying factors. Chest 101: 1074-1079, 1992. 
13. Monchi M, Bellenfant F, Cariou A, Joly LM, Thebert D, Laurent I, Dhainaut JF and Brunet F: Early predictive factors of survival in the acute respiratory distress syndrome. A multivariate analysis. Am J Respir Crit Care Med 158: 1076-1081, 1998.

14. Doyle RL, Szaflarski N, Modin GW, Wiener-Kronish JP and Matthay MA: Identification of patients with acute lung injury. Predictors of mortality. Am J Respir Crit Care Med 152: $1818-1824,1995$.

15. Eisner MD, Thompson T, Hudson LD, Luce JM, Hayden D, Schoenfeld D and Matthay MA; Acute Respiratory Distress Syndrome Network: Efficacy of low tidal volume ventilation in patients with different clinical risk factors for acute lung injury and the acute respiratory distress syndrome. Am J Respir Crit Care Med 164: 231-236, 2001.
16. Page B, Vieillard-Baron A, Beauchet A, Aegerter P, Prin S and Jardin F: Low stretch ventilation strategy in acute respiratory distress syndrome: Eight years of clinical experience in a single center. Crit Care Med 31: 765-769, 2003.

17. Esteban A, Anzueto A, Frutos F, Alía I, Brochard L, Stewart TE, Benito S, Epstein SK, Apezteguía C, Nightingale P, et al: Characteristics and outcomes in adult patients receiving mechanical ventilation: A 28-day international study. JAMA 287: 345-355, 2002. 